\title{
The Sardinian IDDM Study: 1. Epidemiology and geographical distribution of IDDM in Sardinia during 1989 to 1994
}

\author{
M. Songini ${ }^{1}$, L. Bernardinelli ${ }^{2}$, D. Clayton ${ }^{3}$, C. Montomoli $^{2}$, C. Pascutto ${ }^{2}$, M. Ghislandi ${ }^{2}$, D. Fadda ${ }^{2}$, G. F. Bottazzo ${ }^{4}$, \\ and the Sardinian IDDM Study Groups* \\ ${ }^{1}$ Department of Internal Medicine, Ospedale S. Michele, Cagliari, Italy \\ ${ }^{2}$ Dipartimento di Scienze Sanitarie Applicate e Psicocomportamentali, Università di Pavia, Pavia, Italy \\ ${ }^{3}$ Medical Research Council Biostatistics Unit, Institute of Public Health, Cambridge, UK \\ ${ }^{4}$ Department of Immunology, St. Bartholomew's and Royal London School of Medicine and Dentistry, London, UK
}

Summary Analysis of the geographical variation of risk for a disease is a key issue in descriptive epidemiology and may provide useful suggestions for planning further studies to identify the underlying causes. We adopted a Bayesian approach to investigate the geographical distribution of insulin-dependent diabetes mellitus (IDDM) incidence rate across Sardinia. Data on incidence of IDDM in children aged under 15 years (619 IDDM cases) in Sardinia was obtained by the Sardinian Eurodiab ACE register. The overall completeness of ascertainment was: $91.3 \%$. The average yearly standardized incidence rate for the years 1989-1994 was 33.24 per 100000 (95\% C.I. 30.60, 35.88), which is the second highest in Europe after Finland. Sex and age-specific risks were higher in males than in females. Considering the variation of IDDM risk according to the age at diagnosis, the risk profile increased up to the 13th year of age for both sexes, being steeper in males. The degree of geo- graphical variation in IDDM risk was small with a slight difference between the highest and the lowest standardized rate across the map. Indeed, even the municipalities at lowest risk in Sardinia showed a risk higher than most European countries. The Sardinian population is genetically atypical, characterized by genetic homogeneity and marked susceptibility to autoimmune diseases. Our finding of a small geographical variation within the island coupled with a marked temporal trend previously observed in data on military conscripts could be interpreted as evidence of a relatively recent environmental aetiological factor that was uniformly distributed across the island and had its effect in a genetically predisposed population. [Diabetologia (1998) 41: 221-227]

Keywords Sardinia, childhood IDDM, incidence, statistics, epidemiology, Bayesian analysis, geographical distribution.
The study of the variation in space and time of disease risk may provide important clues about its aetiology [1-3] and also useful suggestions for planning further studies aimed at investigating the underlying causes. The high incidence of insulin-dependent diabetes mel-

* for the composition of the Groups see acknowledgements

Received: 10 April 1997 and in revised form: 22 September 1997

Corresponding author: Dr. M. Songini, Department of Internal Medicine, Ospedale S. Michele, 1-09134 Cagliari, Italy; e-mail: songinim@tin.it

Abbreviations: SR, Standardized rate; CI, confidence interval; $\mathrm{PP}$, posterior probability; IR, incidence rate; $\mathrm{CB}$, credible band. litus (IDDM) observed in Sardinia and its peculiar genetic characteristics make Sardinia an interesting place to investigate the epidemiology of IDDM.

Previous studies showed that Sardinia has the second highest IDDM incidence (30.2/100000 personyears [4]) after Finland (35.7/100000 person-years [5]). A recent analysis of the Sardinian conscripts' register indicated that, like in Finland [5, 6], IDDM risk has been progressively increasing in Sardinia since the 1960s [3, 7, 8].

The Sardinian population is genetically distinct from all other Mediterranean and European populations because of a pre-historical and historical isolation from continental Italy and more generally from other Mediterranean areas because of the long history of its settlements. This population 
Table 1 Sex and age incidence rate, standardized rates and number of IDDM cases in Sardinia, 1989-1994

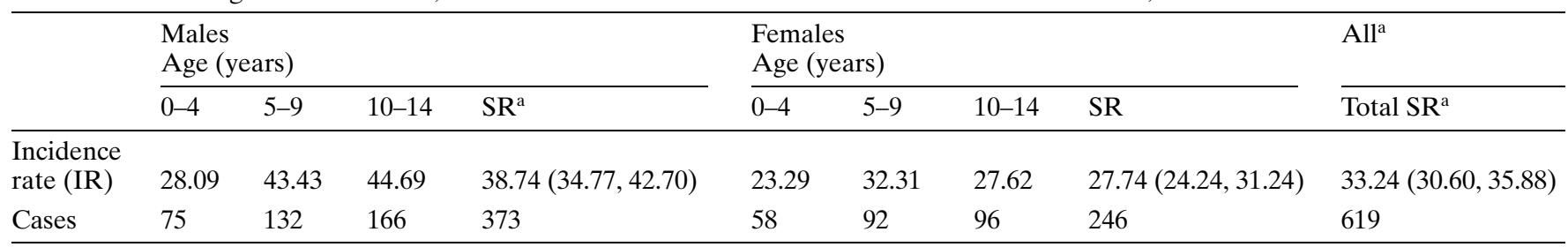

${ }^{a}$ Age-standardized incidence rate $(95 \% \mathrm{CI})$

originated from an early split in the Caucasoid group [9-11].

The main aim of this paper is to study the geographical variation of IDDM incidence rate in children aged under 15 years across the 366 municipalities of Sardinia, using the Eurodiab ACE population-based register in Sardinia for the period 19891994. We adopted a Bayesian approach to filter out the random variation of the estimates due to the small number of events in each geographical (municipality)/temporal (1-year age) unit. Furthermore, we report the sex and age distribution of incidence for the study period.

\section{Subjects and methods}

Study population: The estimate of the population at the 1991 census provided by the Italian Istituto Centrale di Statistica (ISTAT) was of 1648248 residents [12]. The $0-14$ year-old population consisted of 303958 children, 157068 males and 146890 females.

Case definition and ascertainment: IDDM cases were defined according to the diagnosis of idiopathic IDDM as stated by a physician, as in most diabetic registries [13]. Other inclusion criteria for this study were: 1) date of the first insulin injection before 15th birthday and between 1 January 1989 and 31 December 1994; 2) place of residence within the study region at the date of the first insulin injection. Primary case ascertainment was based on hospital records, notification from family practitioners and paediatricians. A secondary independent source of data was the local IDDM patients' association (ADIG Sardegna). The estimated completeness of ascertainment was $91.3 \%$, calculated by the 'capture-recapture' method [14].

Data collection: A standard case record form was used to collect the data. The local investigator of the Eurodiab ACE study provided local collaborators with a case record form, which was sent back to the local investigator whenever a case arose. The recorded variables included case and centre identification, initials, date and place of birth, actual and past residences, gender, date of clinical diagnosis and date of first insulin injection.

Statistical analysis: Incidence rates were calculated as the number of newly diagnosed diabetic cases per 100000 person-years for the age groups $0-4,5-9$ and $10-14$ years. We also calculated the male and female age-specific incidence rates and the directly standardized rates (SR) using a reference population comprising equal numbers in each of the age- and sex-specific categories. The $95 \%$ confidence intervals (CI) for these SRs were calculated using the Gaussian approximation to the Poisson log-likelihood [15].

In order to study the geographical variation of IDDM risk, we filtered out the random variation and mapped the smoothed estimates of SRs at the smallest administrative area in the region, i.e. the municipality. We estimated the area-specific smoothed SRs using a Bayesian approach fully described previously $[3,16,17]$. The map of SRs was accompanied by two maps of the posterior probability (PP) that each area has an SR greater than a given reference value. The PP is the Bayesian equivalent of the $p$-value as defined by Meng and Dempster [18]. In our analysis, we chose the following reference values: (a) the SR in Finland and (b) the median SR over all Sardinian municipalities. The two corresponding PP maps allowed us to identify those areas in which (a) risk is greater than or equal to the highest rate in Europe and (b) risk is particularly high or low by comparison with the median risk in the region. We subdivided the range of PP $(0-1)$ into five intervals $(<0.10,0.10-0.25,0.25-$ $0.75,0.75-0.90,>0.90)$. A map of PP can be interpreted as follows. A value of PP higher than 0.90 strongly indicates that the $\mathrm{SR}$ is higher than the reference value, while a PP smaller than 0.10 indicates that the SR is lower than the reference value. In those areas where PP falls in the fourth interval (0.75-0.90) there is an indication that the SR is higher than the reference value. Similarly, in those areas where PP belongs to the second interval (0.10-0.25) there is an indication that the SR is lower than the reference value. Finally, when the value of PP falls in the central interval $(0.25-0.75)$ there is no evidence of whether the area-specific SR is higher or lower than the reference value.

In order to filter out the random variation of the age-sexspecific incidence rates (IR), we estimated the age-specific IRs by sex using a Bayesian method [19]. The resulting agespecific IR profile is smoothed and hence more interpretable from an epidemiological point of view. For each IR profile the corresponding $95 \%$ credible band (CB), which is the Bayesian equivalent of a $95 \%$ confidence band, was calculated.

Computational details: We fitted the Bayesian model for mapping the area-specific SRs using the software package BUGS [20] and analysed the age-specific profile of IDDM risk using BEAM [21]. We performed the computing on the SUN system SPARC center 2000 owned by the Italian National Research Council (C.N. R.) - Istituto di Analisi Numerica, Pavia.

\section{Results}

In each sex and age-group, the maximum likelihood estimates of IR and the number of IDDM cases observed in Sardinia during the study period are shown in Table 1. The sex-specific and the overall age standardized incidence rates (SR) with their correspond- 


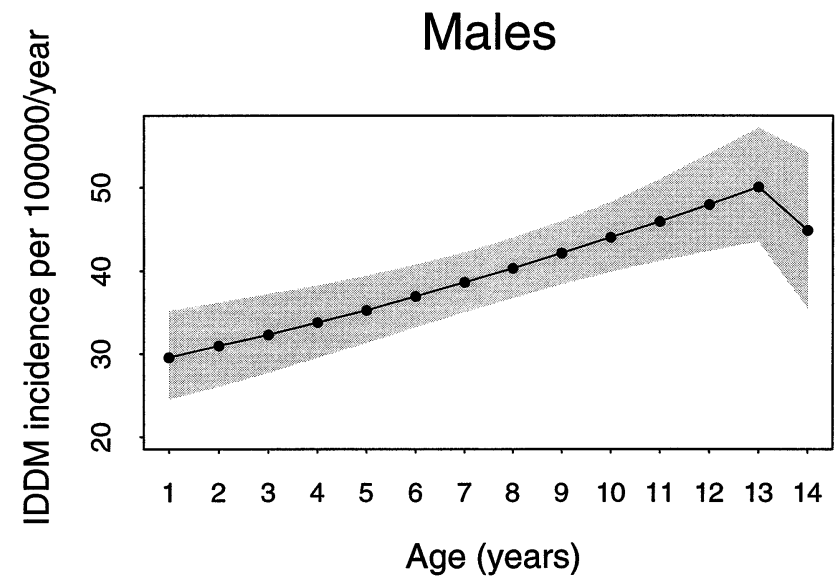

Fig.1. Sex-specific incidence rates by 1-year age-group with corresponding $95 \%$ credible bands

ing $95 \%$ CI are also reported. During the period 1989-1994, the overall SR in Sardinian children aged under 15 years was 33.24/100000 person-years and it turns out to be higher in males than in females (38.74 and 27.74, respectively). There was a male excess in incidence and the male to female ratio was 1.4. About $21 \%$ of the newly diagnosed children was under 5 years of age at the time of diagnosis. In both sexes the largest proportion of childhood IDDM cases ( $44.5 \%$ in males and $39 \%$ in females) was diagnosed among 10-14-year-olds. The highest age group incidence rate was in males 44.69/100000 personyears among 10-14-year-olds, and in females 32.31/ 100000 person-years among 5-9-year-olds.

The profile of the sex-specific incidence rates by 1year age group is reported in Figure 1 together with their corresponding $95 \% \mathrm{CB}$. Since the number of children diagnosed before their first birthday was very small ( 8 cases, $1.3 \%)$ the IR estimate for this age group was omitted. The difference in steepness between the profiles of the two sexes is striking. In both profiles the highest incidence was around 13 years of age.

Figure 2 a shows the map of SR by municipalities, while Figure $2 \mathrm{~b}$ and $\mathrm{c}$ shows the PP calculated using the Finnish SR and the median SR over all the municipalities as reference values, respectively. The areaspecific SRs range from 24/100000 person-years to $42 / 100000$ person-years among the municipalities. The quartiles of the area-specific SRs distribution are: $\mathrm{P} 5=28.75, \mathrm{P} 25=31.95, \mathrm{P} 50=35.21, \mathrm{P} 75=36.76$, $\mathrm{P} 95=38.67$.

From Figure $2 \mathrm{a}$ it emerges that all the municipalities at higher risk are situated in the central-western part of Sardinia, while most of the lower risk areas lie in the north-western part of the island. Nevertheless, there is no great difference between the highest and the lowest SR throughout the map.

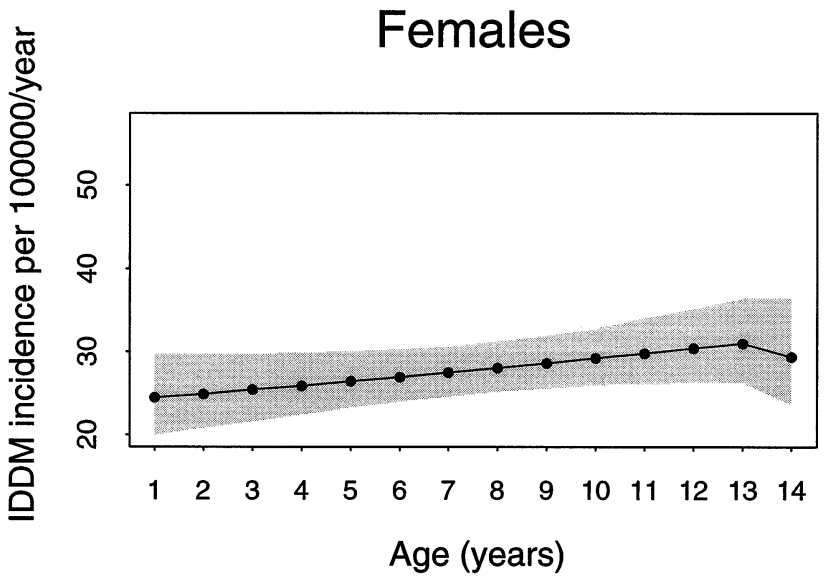

If we compare the area-specific SRs with the Finnish SR on the basis of Figure $2 b$, it emerges that all the municipalities at high risk highlighted in Figure 2 a have their corresponding PP falling in the fourth interval; this means that for these areas there is an indication that the SRs are actually higher than the Finnish rate. No municipalities showed a PP higher than 0.9. If we compare Figures $2 \mathrm{a}$ and $2 \mathrm{c}$, it emerges that most of the areas at high risk, i. e. those falling in the fifth interval in Figure 2 a, do have a PP greater than 0.9. This means that these areas have a SR significantly higher than the median regional risk. The same applies to the areas at low risk: for all areas with an SR falling into the first category, the PP in Figure 2c is lower than 0.1. Two areas from centralwestern Sardinia showed a risk greater than that of Finland and than the median risk of the island.

Figure 3 shows a map of the four Sardinian provinces, with the corresponding estimated completeness of ascertainment. By comparison with the SRs map in Figure $2 \mathrm{a}$, IDDM risk seems to be higher in areas with higher completeness.

\section{Discussion}

IDDM is one of the most frequent chronic diseases in children and young adults and it represents a major public health problem because of its associated risk of long-term complications and premature death.

Sardinia has a very high incidence of IDDM. The overall SR ranks second in Europe after Finland and is much higher than in any other Italian region for which IDDM incidence data are available [22-26].

IDDM risk is higher in males than in females, as already reported $[8,27]$. Considering the variation of IDDM risk according to the age at diagnosis, the risk profile increases up to 13th year of age both for males and females, but the profile is steeper in males. In general, the lowest incidence rates are observed in the 0-4 age-group and the highest in the 5-9 for females and 10-14 age-groups for males. Of the newly diagnosed children $21 \%$ were under 5 years of age 
IDDM incidence (per 100,000/year)

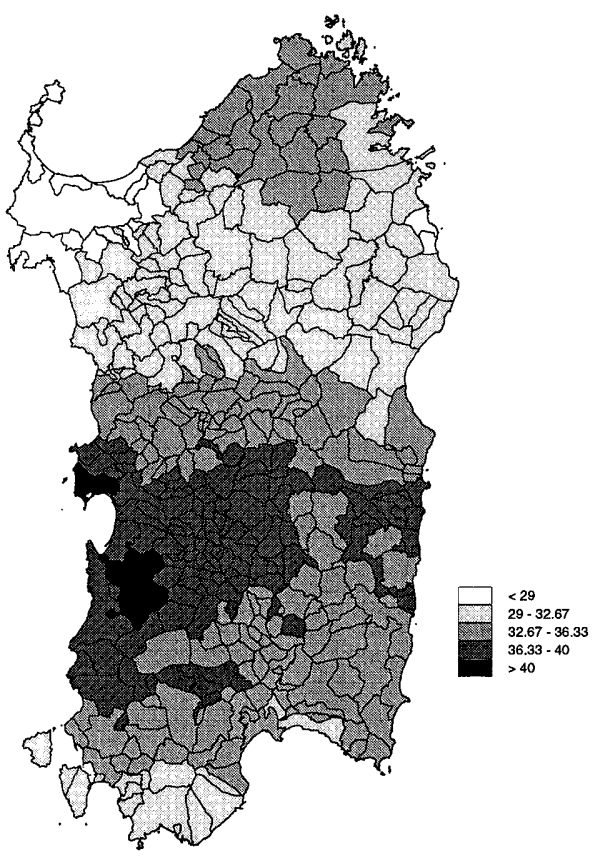

a

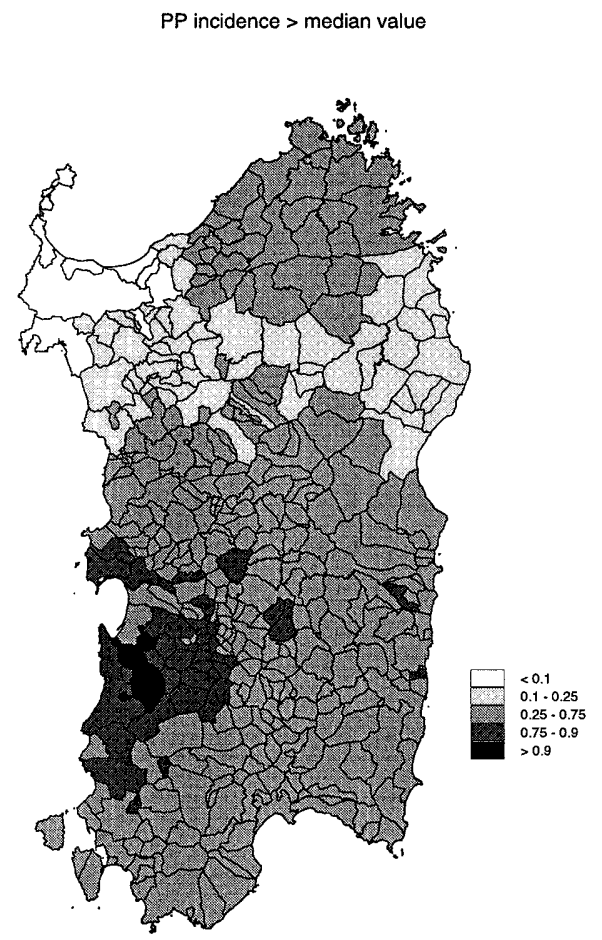

C

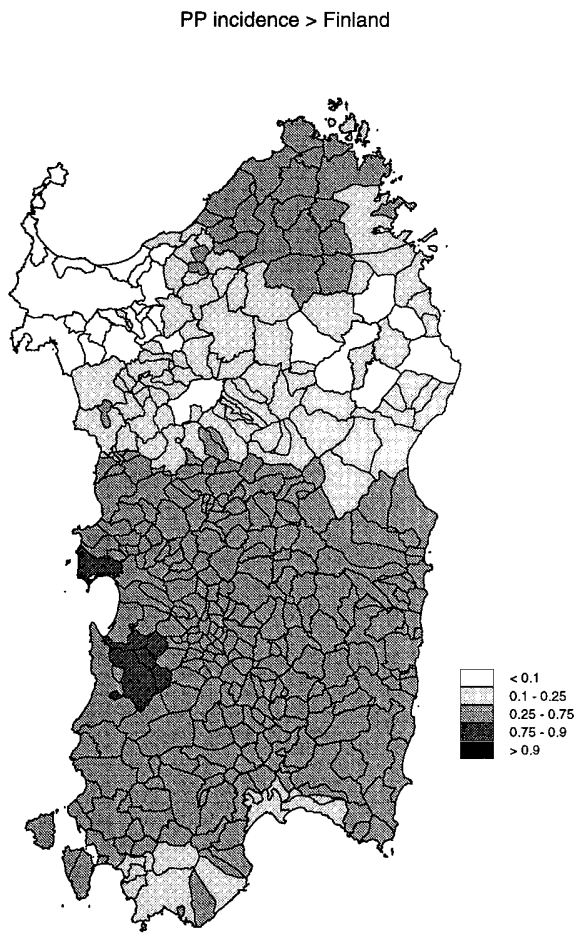

b
Fig. 2. (a) IDDM standardized incidence rates (100000/year) in the 366 Sardinian municipalities; (b) Posterior probability that each area-specific risk is higher than the Finnish rate; (c) Posterior probability that each area-specific risk is higher than the median Sardinian rate

at the time of diagnosis. These results are similar to those obtained for the Finnish population $[8,28]$.

In this paper we analysed the geographical variation of IDDM incidence as observed during the period 1989-1994 at the smallest geographical scale (municipalities). Using a Bayesian approach, we filtered out the Poisson random variation. We found a small amount of geographical variation: all areas are at high risk and there is a slight difference between the highest and the lowest SR. The extent of geographical variation is likely to be further reduced if the ascertainment was the same in all areas. However, we were able to identify two areas from central-western Sardinia in which risk was greater than the overall Finnish risk and greater than the median risk in the island.

Previous studies [3,7] of IDDM as observed at the military examination of 18-year-old male conscripts born in Sardinia during the period 1936-1973 showed a marked overall increasing time trend of IDDM risk (sharp increase from the early 1960s) that cannot be explained in terms of variation in genetic susceptibili- 


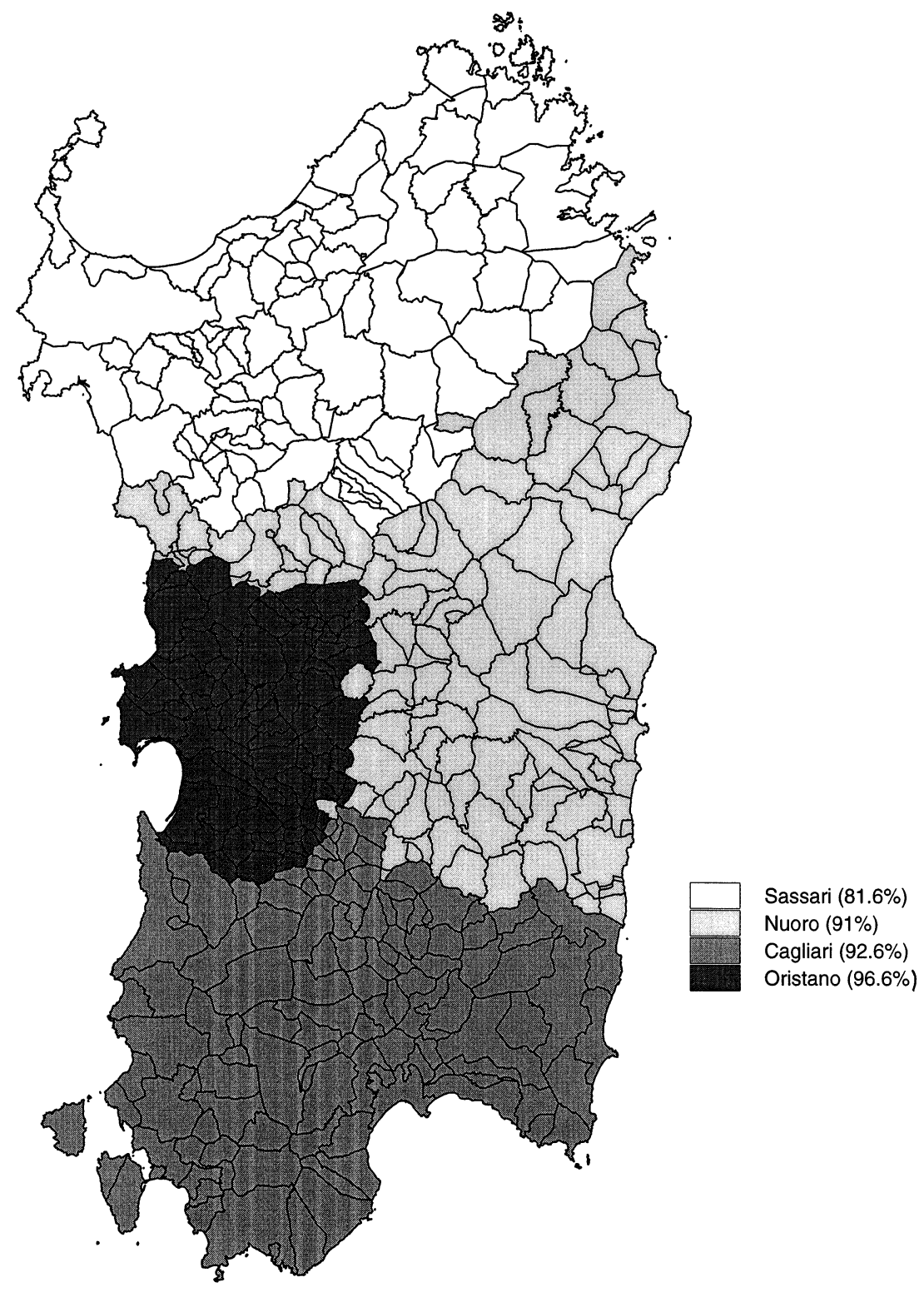

Fig.3 Completeness of ascertainment in the four Sardinian provinces

ty to IDDM of Sardinians, which are a genetically distinct and stable population.

The lack of geographical variation in IDDM risk across Sardinia coupled with the marked temporal trend observed in the military conscript data may suggest that a relatively recent environmental factor uniformly distributed in the territory exerted its action in a population that is genetically predisposed to autoimmune diseases.

A possible indication emerging from these results is that it would be very difficult to identify the implicated factors in Sardinia because of its geographical uniform distribution. On the other hand the Sardinian population is particularly suitable for studying the genetic susceptibility to IDDM because of its peculiar genetic characteristics.

Acknowledgements. This work was supported by grants from The Centro Studi of the Italian Ministry of Health (contractno. 500.4/RPS 92/17.4/D/1337), the NCI (grant-no. 5ROlCA61042), ASRIS (Sardinian Association for the Study of IDDM) in Cagliari, The Autoimmune Disease Charitable Trust in London, UK, MURST $60 \%$, and the ISS (Istituto Superiore di Sanitz', Rome) (grant-no. 96/C/T1). Expert secretarial assistance was provided by Enrica Sollaino.

We wish to thank the Italian National Research Council (CNR), Istituto di Analisi Numerica of Pavia for allowing us to make use of their computing facilities free of charge. We also wish to thank Efisio Agus, Paolo Pinna and Roberto Murgia (Novo Nordisk, Lifescan and Lipha) for helping us in collecting the EURODIAB ACE data from the various Sardinian collaborating centres. 


\section{The Sardinian IDDM Study Groups}

General management: Overall scientific and administrative responsibility: G.F. Bottazzo, London, UK

General Co-ordinator: M. Songini, Cagliari, Italy

Local Overall Responsibility: A. Balestrieri, Cagliari, Italy

Secretary/Administrator: M. Porceddu, Cagliari, Italy

The Epidemiology Study Group

Responsible: M. Songini, Cagliari

Territorial Co-ordinators: R. Cirillo, Cagliari, A. Filigheddu, Sassari, F. Mastinu, Oristano, G. Pala, Nuoro

Participants: L. Addis, Tempio; S. Anedda, Cagliari; E. Angius, Cagliari; F. Atzeni, ADIG-Sardegna; S. Atzori, ADIG-Sardegna; L. Bellu, Alghero; P. Bulciolu, Tempio; A. Cabras, ADIG-Sardegna; S. Cabras, Oristano; G. M. Cambosu, Oristano; L. Carboni, Cagliari; L. Carreras, Guspini; A. Casu, Caglian; M. Chessa, Cagliari; M. A. Chessa, Carbonia; A. Cicalò, Nuoro; R. Cirillo, Cagliari; C. Clausi, Nuoro; D. Cocco, Cagliari; M. T. Contigiani, Alghero; A. Corda, Iglesias; E. Cossu, Cagliari; G. Delitala, Iglesias; G. Fanciulli, Alghero; F. Farris, ADIG-Sardegna; A. Fenu Cotzia, ADIG-Sardegna; A. Filigheddu, Sassari; G. D. Filigheddu, Tempio; O. Frongia, Oristano; P. Frongia,Cagliari; T. Frulio, Sassari; Z. Gambula, Carbonia; A. Gigante, Sorgono; G. Idda, Bossa; N. Landis, Iglesias; S. LaScala, ADIG-Sardegna; A. Loi, Elmas; S. Lostia, Cagliari; M. Maioli, Sassari; A. M. Marinaro, Sassari; C. Marini, Cagliari; U. Marongiu, Lanusei; A. Massidda, Lanusei; G. Melis, Carbonia; T. Meloni, Sassari; S. Mereu, Sorgono; A.F. Milia, Nuoro; T. Muntoni, Cagliari; E. Murenu, ADIGSardegna; B. Nieddu, Muravera; A.Pacifico, Sassari; G. Pala, Nuoro; C. Pipitone, Tempio; M. Pippia, Cagliari; G. Piredda, Ozieri; G. Pisano, Isili; G. Poddighe, ADIG-Sardegna; R. Ricciardi, Cagliari; F. Sanciu, Olbia; S. Sassu, Tempio; M. Scarpa, Cagliari; E. Secchi, Ozieri; F. Sechi, Ozieri; G. Sgarella, ADIG-Sardegna; V. Sica, Guspini; M. Silvetti, Cagliari; P. Simula, ADIG-Sardegna; F. Solinas, Alghero; M. Soro, Oristano; P. Tronci, Cagliari; L. Vincis, Carbonia

\section{The Statistical Group}

Responsible: M. Songini, Cagliari

Consultants: L. Bernardinelli, Pavia, D. Clayton, Cambridge, R. Feldman, London

Computer Engineers: A. Casanova, M. Terrosu, Cagliari

Laboratory personnel: M. Ghislandi, C. Montomoli,

C. Pascutto, Pavia

The School Children Study Group

Responsible: A. Loviselli, F. Velluzzi, Cagliari

Co-ordinators: G. Delitala, Sassari, S. Mariotti, Cagliari

Consultants: M. Maioli, Sassari

Territorial Co-ordinators: G. Fanciulli, Sassari, P. Mele, Oristano, G. Secci, Nuoro

Laboratory personnel: M. A. Calia, M. A. Cambosu, A. Pilo, S. Serra, Cagliari

Field workers: F. Boi, G. Congiu, M. Diliberto, R. Mastinu, T. Mudadu, S. Murenu, A. Pilleri, M. A. Pinna, E. Rizzolo, Cagliari, and family general practitioners in the provinces.

The Newborn Study Group

Responsible: R. Cirillo, Cagliari
Co-ordinators: E. Angius, Cagliari, G. Cambosu, Oristano, T. Meloni, Sassari, C. Pintor, Cagliari

Central Co-ordinators: E. Cossu, G. Guaita, M.F. Mulas, I. Pelligra, M. Saba, Cagliari

Laboratory personnel: E. Cianchetti, S. Cocco, A. Floris, A. Lai, P. Pidanu, P. Pitzalis, C. Porru, T. Rivano,

A.M. Setteneri

Territorial Co-ordinators: V. Barra, Cagliari; L. Bellu, Alghero; P. Bulciolu, Tempio; F. Cadoni, Cagliari; M. A. Chessa, Carbonia; G. Delitala, Iglesias; S. Erre, Ozieri; M. Falchi, Muravera; A. Flumene, Sassari; G. Idda, Bosa; N. Landis, Iglesias; C. Licheri, La Maddalena; O. Limongelli, S. Gavino; M. Loi, Cagliari; A. M. Marinaro, Sassari; U. Marongiu, Lanusei; A. Masia, Olbia; G. Meloni, Sassari; A.F. Milia, Nuoro; L. Murtas, Oristano; G. Pilo, Sassari; G. Piredda, Ozieri; G. Pisano, Isili; S. Pulina, Tempio; R. Ricciardi, Cagliari; E. Sequi, Sorgono; M. Soro, Oristano; R. Trudu, Cagliari; M. A. Zedda, Cagliari; A. M. Zulato, Sorgono; and the Paediatric general practitioners in Sardinia

Field workers: 12 professional nurses

The Immunological and Genetic Study Group

Responsible: G.F. Bottazzo, London

Co-ordinators: V. Sepe, London

Consultants: E. Bonifacio, Milano; S. Carata, Rome; G. Hitman, London; M. Pirastu, Sassari; J. Sachs, London

Laboratory personnel: Y. Chen, P. Collins, R. Foxon, S. Davey, D. McCloskey; M. Shattock, London

The Emigrant Study Group

Responsible: M. Songini, Cagliari

Co-ordinator: A. Olianas, Pavia

Consultants: E. Bosi, Milan; R. Lorini, Pavia; A. M. Tenconi, Pavia; F. Velluzzi, Cagliari

Laboratory personnel: A. Vitali

External support: Federazione Associazioni Sardi in Italia (FASI) \& Circoli Emigranti Sardi Lombardia

The Environmental Study Group

Responsible: C. Palmas, M. Songini, Cagliari

Co-ordinators: A. Contu, A. Vona, Cagliari

Consultant: D. Colei, Sassari

Laboratory personnel: G. Trova, Sassari

Veterinary Study Group

Responsible: G. Pintori, Sassari

Co-ordinator: M. Fadda, Sassari

Scientific Committee: S. Carta, Roma; R. Del Baglivo, Roma; S. Del Giacco, Cagliari; A. Maida, Sassari; M. Pironi, Roma; G. Pozza, Milano; G. Vicari, Roma

Academic Secretary

Department of Immunology,

St. Bartholomew's and The Royal London School of Medicine and Dentistry, Turner Street, London E1 2AD, UK

Tel.: + 44171377 7109; Fax: + 441717903033 


\section{References}

1. Reunanen A, Åkerblom HK, Käär ML (1982) Prevalence and ten-year (1970-1979) incidence of insulin-dependent diabetes in children and adolescents in Finland. Acta Paediatr Scand 71:839-849

2. Christau B, Åkerblom H, Joner G, Dahlqvist G, Ludvigsson J, Nerup J (1981) Incidence of childhood insulin-dependent diabetes mellitus in Denmark, Finland, Norway and Sweden. A workshop report. Acta Endocrinol 98 [Suppl 245]:68-80

3. Bernardinelli L, Clayton D, Pascutto C, Montomoli C, Ghislandi M, Songini M (1995) Bayesian analysis of spacetime variation in disease risk. Stat Med 14: 2433-2443

4. Green A, Gale EAM, Patterson CC for the EURODIAB ACE Study Group (1992) Incidence of childhood-onset insulin-dependent diabetes mellitus: the EURODIAB ACE study. Lancet 339: 905-909

5. Tuomilehto J, Virtala E, Karvonen M, et al. (1995) Increase in incidence of insulin-dependent diabetes mellitus among children in Finland. Int J Epidemiol 24: 984-992

6. Muntoni S, Songini $M$ and the Sardinian Collaborative Group for Epidemiology of IDDM (1992) High incidence rate of IDDM in Sardinia. Diabetes Care 15 (10):1317-1322

7. Songini M, Loche M, Muntoni SA, et al. (1993) Increasing prevalence of juvenile onset type 1 (insulin-dependent) diabetes mellitus in Sardinia: the military service approach. Diabetologia 36: 547-552

8. Akerblom HK, Reunanen A (1985) The epidemiology of insulin-dependent diabetes mellitus (IDDM) in Finland and in northern Europe. Diabetes Care 8: 10-16

9. Piazza A, Mayr WR, Contu L, et al. (1985) Genetic and population structure of four Sardinian villages. Ann Hum Genet 4: 47-63

10. Cavalli-Sforza LL, Menozzi P, Piazza A (1994) Europe. In: The history and geography of human genes. Princeton University Press, Princeton, New Jersey, pp 255-301

11. Cappello N, Rendine S, Griffo R, et al. (1996) Genetic analysis of Sardinia: data on 12 polymorphism in 21 linguistic domains. Ann Hum Genet 60: 125-141

12. ISTAT (1991) $13^{\circ} \mathrm{Censimento} \mathrm{generale} \mathrm{della} \mathrm{popolazione}$ - Sardegna

13. LaPorte RE, Tajima N, Åkerblom HK, et al. (1985) Geographic differences in the risk of insulin-dependent diabetes mellitus: the importance of registries. Diabetes Care 8 [Suppl 1]:101-107

14. Bishop YMM, Fienberg SE, Holland PW (1974) Discrete multivariate analysis: theory and practice. MIT Press, Cambridge, MA
15. Clayton DG, Hills M (1993) Statistical models in epidemiology. 1st edn. Oxford University Press, Oxford New York Tokyo

16. Bernardinelli L, Montomoli C (1992) Empirical Bayes versus fully Bayesian analysis of geographical variation in disease risk. Stat Med 11: 983-1007

17. Clayton D, Bernardinelli L (1993) Bayesian methods for mapping disease risk. In: Cuzick J, Elliott P (eds) Small area studies in geographical and environmental epidemiology. Oxford University Press, Oxford New York Tokyo, pp 205-220

18. Meng CYK, Dempster AP (1987) A Bayesian approach to the multiplicity problem for significance testing with binomial data. Biometrics 43: 301-311

19. Berzuini C, Clayton D, Bernardinelli L (1993) Bayesian analysis on the Lexis diagram. ISI Bulletin, pp 149-165

20. Thomas A, Spiegelhalter DJ, Gilks WR (1992) BUGS: A program to perform Bayesian inference using Gibbs sampling. In: Bernardo JM, Berger JO, Dawid AP, Smith AFM (eds) Bayesian statistics Vol. 4. Clarendon Press, Oxford UK, pp 837-842

21. Clayton DG (1994) BEAM: A program for Bayesian ecological analysis and mapping. Version 2.02, Medical Research Council, Biostatistics Unit, Institute of Public Health, Cambridge, UK

22. Arpi ML, Italia S, Motta RM, et al. (1994) Incidence of type I diabetes in the district of Catania, Sicily. Acta Diabetol 31(1):37-39

23. Cherubini V, Cantarini M, Ravaglia E, Bartolotta E (1994) Incidence of IDDM in the Marche Region, Italy. Diabetes Care 17(5):432-435

24. Mazzella M, Cotellessa M, Bonassi S, et al. (1994) Incidence of type I diabetes in the Liguria Region, Italy. Results of a prospective study in a 0- to 14-year age-group. Diabetes Care 17(10):1193-1196

25. Tenconi MT, Devoti G, Albany I, et al. (1995) IDDM in the province of Pavia, Italy, from a population-based registry. A descriptive study. Diabetes Care 18(7):1017-1019

26. Sebastiani L, Visalli N, Adorisio E, et al. (1996) A 5-year (1989-1993) prospective study of the incidence of IDDM in Rome and in the Lazio region in the age-group 014 years. Diabetes Care 19(1):70-73

27. Diabetes Epidemiology Research International Group (1988) Geographic patterns of childhood insulin-dependent diabetes mellitus. Diabetes 37(8):1113-1119

28. Padaiga Z, Tuomilehto J, Karvonen M, et al. (1997) Incidence trends in childhood onset IDDM in four countries around, the Baltic sea during 1983-1992. Diabetologia 40: 187-192 